\title{
An open-pored gelatin/hydroxyapatite composite as a potential bone substitute
}

\author{
William B. Hillig $\cdot$ Y. Choi $\cdot$ S. Murthy $\cdot$
}

N. Natravali $\cdot$ P. Ajayan

Published online: 19 August 2008

(C) Springer Science+Business Media, LLC 2008

Erratum to: J Mater Sci: Mater Med (2008)

\section{9(1):11-17 \\ DOI 10.1007/s10856-007-0154-x}

In the HTML, online PDF, and printed version of this article, Swati Murthy's name was misspelled. It appears correctly here. This article was published in Volume 19, Issue 1, pages 11-17 of the Journal, and can be found online at the DOI number listed below.

The online version of the original article can be found under doi:10.1007/s10856-007-0154-x.

W. B. Hillig $(\varangle) \cdot$ Y. Choi · P. Ajayan

Department of Material Science and Engineering, Rensselaer Polytechnic Institute, Troy, NY 12180-3590, USA

e-mail: hilliw@rpi.edu

\section{S. Murthy}

Department of Electrical Engineering, Princeton University, Princeton, NJ 08544, USA

N. Natravali

Department of Biological and Environmental Engineering,

Cornell University, Ithaca, NY 14853-5701, USA 